\title{
An Outranking Multicriteria Method for Nominal Classification Problems with Minimum Performance Profiles
}

\author{
Maisa M. Silva (D), Ana Paula H. de Gusmão, and Ana Paula C. S. Costa \\ Center for Decision Systems and Information Development (CDSID), Universidade Federal de Pernambuco, Av. da Arquitetura, \\ Cidade Universitária, 50740-550 Recife-PE, Brazil
}

Correspondence should be addressed to Maisa M. Silva; maisa@cdsid.org.br

Received 22 February 2019; Revised 5 April 2019; Accepted 7 April 2019; Published 5 May 2019

Guest Editor: Juan C. Leyva-Lopez

Copyright (C) 2019 Maisa M. Silva et al. This is an open access article distributed under the Creative Commons Attribution License, which permits unrestricted use, distribution, and reproduction in any medium, provided the original work is properly cited.

\begin{abstract}
In recent years, nominal classification problems have gained importance, especially in the context of strategic management of organizations. In this sense, this paper presents a novel multicriteria nominal classification method, derived from the concepts of PROMETHEE, applied to use in problems characterized by minimum performance profiles (MMP) for the classes. The main advantages of this proposal are criterion and alternative flexibility for classes; robustness, because it uses the concepts of a wellknown method (PROMETHEE); and usefulness, because many real situations are characterized by MMP for the classes. Moreover, a real-world example is presented: a retailer's assignment in a bank, showing the applicability of the method. The proposal of a new multicriteria nominal classification method emerges from a need to devise a more flexible and realistic procedure for characterizing classes because the feature of criterion and alternative flexibility for classes has not been addressed in any extant multicriteria nominal classification procedure. The present proposal thereby endeavors to address this deficit in the multicriteria field.
\end{abstract}

\section{Introduction}

Multicriteria decision problems represent situations in which the decision maker (DM) confronts at least two alternatives, and the decision aims to achieve multiple objectives that are, most of the time, conflicting [1]. In these problems, the DM may pose the problem by choosing, ranking, classifying, or describing the alternatives. These modes of framing are referred to as problematics [2].

Classification allows a DM to assign alternatives to predefined classes, a process known as supervised assignment, or to nonpredefined classes, which is known as unsupervised classification and typically referred to as clustering. In both cases, according to [3], this problematic has compelling implications in numerous areas related to practical or scientific issues, such as the following fields: inventory classification [4-6]; supplier classification [7]; risk analysis in pipelines [8]; and cooperation classification [9]. For more detailed information on clustering approaches that permit allocation of alternatives into nonpredefined classes, see [10-15].

In the context of a supervised assignment, the predefined classes can either be ordered or not ordered. Sorting applies to cases involving ordered classes, and classification applies to problems involving nonordered classes, also known as nominal classification problems [3]. According to [17], in sorting problems, classes are either represented by the lower and upper bounds of a limiting profile (as in the case of ELECTRE TRI) or by a central profile as in [18].

The method proposed herein enables the allocation of alternatives into predefined classes. The proposal of a new multicriteria nominal classification method based on MPP (minimum performance profiles) emerges from a need to devise a more flexible and realistic procedure for characterizing classes, using concepts already associated with multicriteria methods. It is, however, worth noting that the method is easily adapted to apply to other types of problems with classes characterized by maximum performance profiles, central profiles, or alternatives representing the typical element of a class and pursuant to a proximity index. As such, this proposal's main advantages are as follows: criterion and alternative flexibility for classes; robustness, conceptualized in terms of a well-known method (i.e., PROMETHEE); and usefulness. 
The paper is structured as follows. The next section-Theoretical Contributions-highlights the importance of methods devoted to nominal classification problems by outlining several potential applications and presents the gap of the literature which motivated the development of the method proposed herein. The section Materials and Methods comprises two subsections: the first subsection is devoted to describe nominal classification problems and the aim of the proposed method; the second subsection-Proposed Method: Features and Definitions-first presents this proposed method in detail, along with a summary of PROMETHEE concepts, assumptions, and notations, and goes on to describe the conditions and features used in the proposed nominal classification method. The section Application presents an illustrative example and a comparison among several nominal classification methods, and it is followed by a robustness analysis of the proposed method. The following section provides a discussion of the results. Finally, the section Conclusions presents some conclusions and final remarks.

\section{Theoretical Contributions}

Although [19] assert that, in recent years, nominal classification problems have grown more important, mainly in the context of managing of organizations and institutions, the same authors also acknowledge that this has not yielded a correspondingly vast literature on multiple criteria nominal classification. Indeed, due to its competitiveness, modern society is on a constant quest for patterns or homogeneity aimed at more effective implementation of its policies and strategies.

Five potential applications of multicriteria nominal classification problems are described in [19]. One such application is the problem of identifying or determining the most accurate disease class(es) for a given patient, based on his/her symptoms. Thus, patients assigned to the same class (es) of disease may be subject to identical medical procedure(s). Alternatively, the process of recruiting soldiers could also be handled as a nominal classification problem, as each candidate is assessed according to multiple individual features (i.e., physical fitness, intelligence, motivation, teamwork skills, and mental faculties) and subsequently assigned to one of several special core skill task units, where they will undertake special training courses. Another potential application relies on the fact that alerting people to information about public health events and risks, via social media, should be pursued differently, according to the specific type of user targeted. Whenever possible, users are characterized in terms of various features, such as age, health condition, frequency of travel, and degree of dependence on social networks. Users can then be assigned to one of several social groups, like "younger," "middle-aged," or "elderly." The fourth potential application concerns the problem of assigning responsibilities to risk owners (i.e., a person or entity responsible for managing an assigned risk). This is normally performed in risk management. Finally, the fifth potential application involves the task of determining the type of instrument(s) for issuing environmental policy best suited to manage each environmental issue in a way that achieves desired outcomes strategically, effectively, and efficiently. This is especially important, because policies play a key role in addressing complex environmental and health problems, and consequently, in improving the state of the environment.

In the multicriteria field, many approaches have been proposed to address the sorting problematic. Evidently, the ELECTRE TRI method $[20,21]$ is "the most popular", according to [16], and "the most used", according to [3], method of ordinal classification and based on limiting or boundary profiles. Adaptations of this method are exemplified by many works, including ELECTRE TRI-C, based on characteristic or central reference profile [22]; ELECTRE TRI-NC, where each class is defined by several central reference actions [23]; and ELECTRE-SORT [24], where classes are defined by central limiting profiles that can also be incomparable. It is possible to cite additional methods, along with the ELECTRE TRI, that deal with ordinal classification: PROMSORT [25]; AHPSort [26]; THESEUS [27]; TRICHOM [28]; N-TOMIC [29]; FlowSort [17]; a pairwise comparison-based method [18]; ORCLASS [30]; and a hybrid method based on AHP method, a veto system, and the K-means algorithm [31]. However, there are substantially fewer methods developed to address nominal classification problems than methods, proposed in the last few decades, intended to aid DMs in choosing, ranking, and even sorting problems.

Most current methods designed to handle nominal classifications problems are procedures based on reference actions, also called central profiles. Indeed, [32] argued that such problems usually require determination of whether an alternative $a$ is close or similar to alternative $b$, or to an alternative representing a typical element of a class-also known as a prototype, and [33] explained preferences for criteria in terms of weights reflecting the importance of the criteria, relative to all classes. As such, the latter mode does not rely on a reference profile, as the weights define the classes. Moreover, [34] treated a problem defining nonordered classes by the least typical representative of each, referred to as the entrance threshold, and [35] defined each class by a given number of features, conditions, or constraints. Problems characterized by MPPs have drawn the attention of multiple researchers. For instance, [36] employed a nominal classification method aimed at enabling a construction company to select managers for different roles (i.e., the classes), according to different competencies and MPPs for classes; [37] applied the NeXClass nominal classification method to the project of assigning military students to one of multiple classes, characterized by MPPs consistent with predefined criteria; and $[34,38,39]$ presented a real-world application of a classification method, using MPPs, to a problem in a banking environment.

Indeed, according to a literature review on classification methods, the feature of criterion and alternative flexibility for classes has not been addressed in any extant multicriteria nominal classification procedure, except in the method proposed by [33]. Although the proposal of [33] evaluates the alternatives, according to some criteria, the classification method relies on a binary linear programming approach, akin to a portfolio problem maximizing a valued objective 
function. The present proposal thereby endeavors to address this deficit in the multicriteria field. The feature of criterion and alternative flexibility for classes will be fully discussed and described in the second subsection of the next section.

\section{Materials and Methods}

3.1. Nominal Classification Problems. Classification (nominal and ordinal) problems aim to assign alternatives to predefined classes, according to some evaluation criteria, thus, giving the following: a set of $n$ alternatives $A=\left(a_{1}, a_{2}, \ldots, a_{i}\right)$, where $i=1, \ldots, n$; a set of $m$ criteria $G=\left(g_{1}, g_{2}, \ldots, g_{j}\right)$, where $j=1, \ldots, m$; a set of $c$ classes $C=\left(C_{1}, C_{2}, \ldots C_{k}\right)$, where $k=1, \ldots, c$; and $c$ sets of MPPs, for each class $k$ and for all $m$ criteria, $B_{k}=\left(b_{k 1}, b_{k 2}, \ldots, b_{k j}\right)$-; the aim is to assign each alternative in a specific class by evaluating the alternative pursuant to the criteria relevant to the different classes and also according to the MPPs defined for each class. Mathematically, each class $C_{k}$ is represented by a $B_{k}$ of MPPs. Further, each class is defined by a unique MPP. These concepts are represented, schematically, in Figure 1.

According to Figure 1, an alternative $a_{i}$ must meet the minimum performance profile $b_{k j}$ for each criterion $g_{j}$, defined for a specific class $k$, to be able to belong to this class. The problem presented in Figure 1 is a sorting problem, as, when comparing two classes $C_{k}$ and $C_{k-1}$ for all criteria, the MPP required by $C_{k}$ is always greater than that required by $C_{k-1}$.

The main feature distinguishing nominal classification from sorting problems is that, in the first, classes are nonordered regarding the criteria. Figure 2 illustrates this idea for a nominal classification problem characterized by MPPs.

As is observable in Figure 2, the MPP required by some criteria in some classes does not follow an order. To wit, the classes are nonordered. For example, the MPP required for one alternative, to be assigned to class $C_{k}$, is greater than the MPP required for the same alternative to be assigned to class $C_{k-1}$ for criterion $g_{1}$. However, the MPP requirement in the case of criterion $g_{2}$ is greater for the $C_{k-1}$ class than it is for the $C_{k}$ class.

Regarding the methods applicable to multicriteria nominal classification problems, researchers have proposed some modes of assigning alternatives to classes, including the following: [41] proposed the fuzzy nominal classification method PROAFTN; [33] presented a multicriteria decision method with an additive linear function, based on SMART and with linear constraints; [32] developed a method based on the concepts of concordance and discordance; and [19] proposed a nominal classification method based on the concepts of similarity and dissimilarity. There are certainly more nominal classification proposals, such as those from the following researchers: [42], with TRINONFC; [43], with CLOSORT; [34], with NeXClass; [35], with a method based on selectability/rejectability measures; and [44].

As can be seen, there are numerous potential applications of multicriteria nominal classification problems. This is a clear motivation driving the development of the proposal presented in this paper. The problem stated here consists of assigning an alternative to a specific class, considering a set of alternatives, a set of predefined nonordered classes, and a set of evaluation criteria. Also, for each predefined class, the DM defines a MPP for each evaluation criterion, which represents the minimum requirements for the inclusion of an alternative in this class. In that way, the method proposed here differs from the methodological contributions described previously. Our proposal aims to assign each alternative to the most suitable class, or rather, the alternative that outranks the reference profile with a greater magnitude, thereby ensuring coherent classification is coherent.

The next subsection details the aspects of the proposed method, after presenting the general features of the outranking multicriteria approach-more specifically the PROMETHEE, in which the proposal is based.

3.2. Proposed Method: Features and Definitions. Following an outranking multicriteria approach, where two alternatives $a_{1}$ and $a_{2} \in A$ are compared, the result must be expressed as a preference. Therefore, a preference function $\mathrm{F} / \mathrm{F}: \mathrm{A} \times \mathrm{A} \longrightarrow$ $(0,1)$, representing the intensity of preference of alternative $a_{1}$ regarding alternative $a_{2}$, must be recognized, such that $[2,45-$ $48]$.

(i) $\mathrm{F}\left(a_{1}, a_{2}\right)=0$ means indifference between $a_{1}$ and $a_{2}$, or no preference of $a_{1}$ over $a_{2}$;

(ii) $\mathrm{F}\left(a_{1}, a_{2}\right) \sim 0$ means weak preference of $a_{1}$ over $a_{2}$;

(iii) $\mathrm{F}\left(a_{1}, a_{2}\right) \sim 1$ means strong preference of $a_{1}$ over $a_{2}$;

(iv) $\mathrm{F}\left(a_{1}, a_{2}\right)=1$ means strict preference of $a_{1}$ over $a_{2}$

It is worth stating that the symbol stands for "close to" in the multicriteria literature [45-48].

Among methods for outranking multicriteria, the PROMETHEE, proposed by [48], is particularly simple and suitable method for achieving accuracy, where multiple evaluation criteria are involved [49]. The PROMETHEE methods use six types of preference functions associated with each criterion, as detailed by [48]. These were based on previous methods, such as ELECTRE III (linear criterion), or on preference modeling structures (usual, U-shape, and level criterion). In most practical applications, the six preference types provide the DM with a sufficient level of flexibility [40]. The six types of criteria and their respective descriptions are provided in Table 1.

As presented in Table 1, most types of preference functions used in PROMETHEE have a double threshold: $p$ and $q$. Reference [50] has noted the importance of defining the structure of criteria in classification methods, by a double threshold (i.e., preference and indifference thresholds). According to this author, a double-threshold structure prevents improper classification. To wit, the absence of preference and indifference thresholds can lead to improper judgements between strict preference and indifference among alternatives and profiles of classes. In fact, several multicriteria classification methods, such as ELECTRE TRI or NeXClass, rely on the double-threshold structure.

Further, another justification for the double-threshold structure is that it facilitates avoidance of weak outranking 


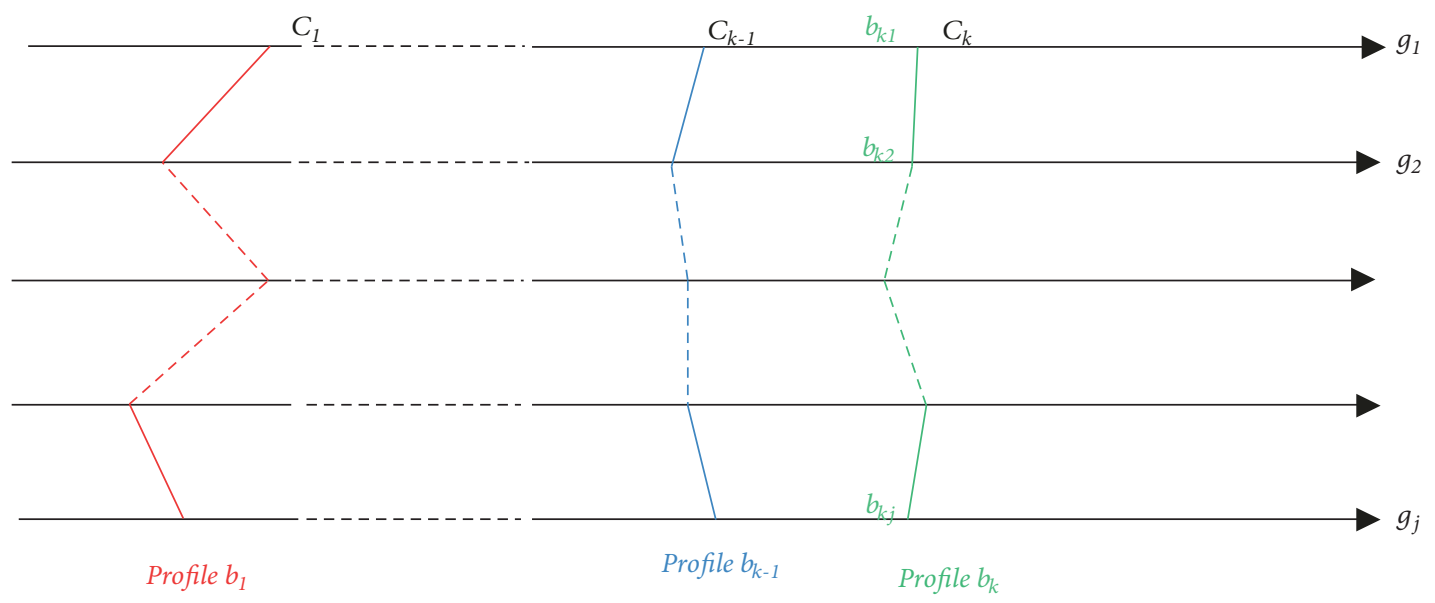

FIGURE 1: Profiles in ordinal classification problem [16].

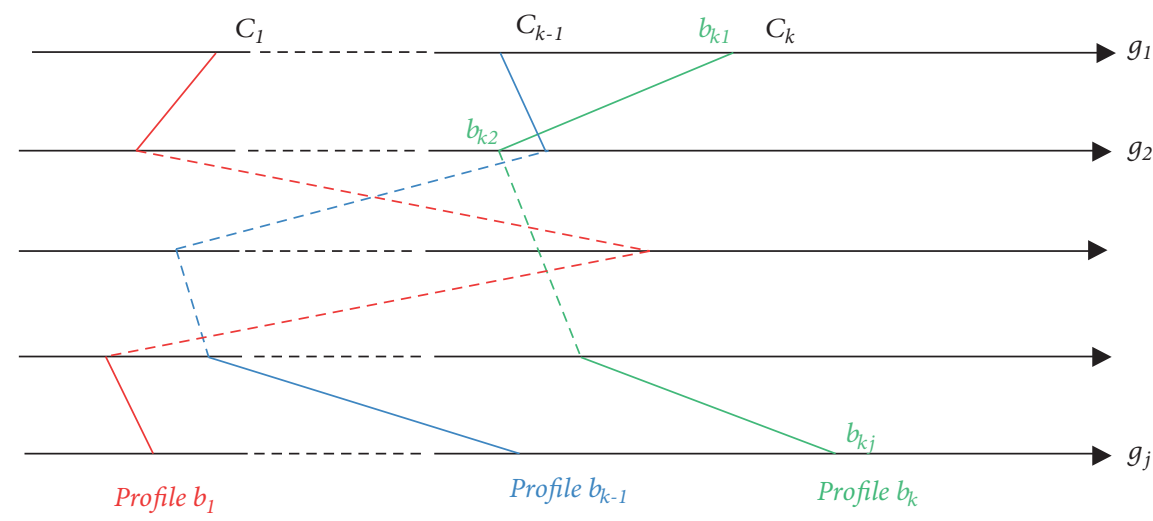

FIgURE 2: Profiles in a nominal classification problem characterized by MPPs.

relations between alternatives and profiles of classes that produce improper assignments to classes. Moreover, given that there must be imprecise and uncertain information about the MPPs, setting indifference and preference thresholds is recommended. Finally, in a case where the DM is absolutely sure about the values for the MPPs, the preference and indifference thresholds can equal zero. Therefore, our approach is flexible in the sense that it can use or not use a doublethreshold structure.

For each pair of alternatives $a_{1}$ and $a_{2} \in A$, one first defines a preference index $\Pi$ for $a_{1}$ regarding $a_{2}$ over all the $m$ criteria. Suppose every criterion $j(j=1,2, \ldots m)$ has been identified as one of the six types considered (Table 1 ), so the preference functions $F_{j}\left(a_{1}, a_{2}\right)$ have been defined for each $j$. The multicriteria preference index $\Pi$ for $a_{1}$ with regard to $a_{2}$ over all the $m$ criteria in the PROMETHEE method is therefore defined as the weighted average of preference functions $F_{j}$ :

$$
\Pi\left(a_{1}, a_{2}\right)=\frac{\sum_{j=1}^{m} \pi_{j} F_{j}\left(a_{1}, a_{2}\right)}{\sum \pi_{j}}
$$

$F_{j}\left(a_{1}, a_{2}\right)$ represents the preference function $F$ of alternative $a_{1}$ regarding $a_{2}$ over the criterion $j$. $\pi_{j}$ represents the weight of criterion $j$.

$\Pi\left(a_{1}, a_{2}\right)$ represents the intensity of preference of the DM of alternative $a_{1}$ over alternative $a_{2}$, given all the criteria simultaneously. It is a value between 0 and 1 :

(i) $\Pi\left(a_{1}, a_{2}\right) \sim 0$ denotes a weak preference of $a_{1}$ over $a_{2}$ for all the criteria,

(ii) $\Pi\left(a_{1}, a_{2}\right) \sim 1$ denotes a strong preference of $a_{1}$ over $a_{2}$ for all the criteria.

In classification problems, nominal or ordinal, the outranking relationships are then generated by comparing alternatives to profiles. This comparison, in the approach proposed in this paper, is made through two indices that validate the claim $a_{i} S B_{k}$. These indices are defined in the following set of terms.

Definition 1 (intensity of membership). For any alternative $a_{i}$ from $A$ and any MPP $B_{k}$ representing class $C_{k}, \Pi\left(a_{i}, B_{k}\right)$ represents the intensity of the membership of $a_{i}$ in $B_{k}$; to wit, the amount of evaluation criteria supports this membership.

$$
\Pi\left(a_{i}, B_{k}\right)=\frac{\sum_{j=1}^{m} w_{k j} F_{k j}\left(a_{i}, B_{k}\right)}{\sum w_{k j}}
$$

$F_{k j}\left(a_{i}, B_{k}\right)$ represents the preference function $F$ of alternative $a_{i}$ regarding the profile $B_{k}$ over the criterion $j$ for the class $C_{k}$. 
TABLE 1: The six types of preference functions used in PROMETHEE [40].

\begin{tabular}{lccc}
\hline Criterion & Type & Parameters & Description \\
\hline Usual & I & None & $\begin{array}{c}\text { It is used for qualitative criteria with few evaluation } \\
\text { levels (up to 5-point-scale) }\end{array}$ \\
\hline $\begin{array}{l}\text { Quasi-criterion (U-shape) } \\
\begin{array}{l}\text { Preference threshold } \\
\text { (V-shape) }\end{array}\end{array}$ & II & $\begin{array}{c}q \text { parameter (indifference } \\
\text { threshold) }\end{array}$ & It is a special case of level one \\
$\begin{array}{l}\text { Pseudo-criterion (Level) } \\
\text { Indifference area (Linear) }\end{array}$ & IV & $\begin{array}{c}p \text { and } q \text { (preference and } \\
\text { threshold) } \\
\text { indifference thresholds) }\end{array}$ & $\begin{array}{c}\text { It is used for qualitative criteria when one needs to } \\
\text { differentiate smaller deviations from large ones }\end{array}$ \\
\hline $\begin{array}{l}p \text { and } q \text { (preference and } \\
\text { indifference thresholds) }\end{array}$ & $\begin{array}{c}\text { It is used for quantitative criteria expressed on a } \\
\text { continuous scale }\end{array}$ \\
Gaussian & VI & Standard deviation & $\begin{array}{c}\text { It is more difficult to structure because its threshold } \\
\text { value is somewhere between the } q \text { indifference } \\
\text { threshold and the } p \text { preference threshold }\end{array}$ \\
\hline
\end{tabular}

Definition 2 (intensity of nonmembership). Having $a_{i}$ from $A$ and any MPP $B_{k}$ representing class $C_{k}, \Pi\left(B_{k}, a_{i}\right)$ represents the amount of evaluation criteria opposed to the membership of $a_{i}$ into $B_{k}$.

$$
\Pi\left(B_{k}, a_{i}\right)=\frac{\sum_{j=1}^{m} w_{k j} F_{k j}\left(B_{k}, a_{i}\right)}{\sum w_{k j}}
$$

$F_{k j}\left(B_{k}, a_{i}\right)$ represents the preference function $F$ of the profile $B_{k}$ regarding an alternative $a_{i}$ over the criterion $j$ for the class $C_{k}$.

The sets of parameters for application of the present nominal classification proposal are as follows:

$$
\begin{aligned}
& W_{k}=\left(w_{k 1}, w_{k 2}, \ldots, w_{k j}\right) \text { : the set of all criteria weights } \\
& \text { for class } k \text {; } \\
& B_{k}=\left(b_{k 1}, b_{k 2}, \ldots, b_{k j}\right) \text { : the set of each MPP for each } \\
& \text { criterion } j \text { in class } k \text {; } \\
& P_{k}=\left(p_{k 1}, p_{k 2}, \ldots, p_{k j}\right): \text { the set of each preference } \\
& \text { threshold for each criterion } j \text { in class } k \text {. } \\
& Q_{k}=\left(q_{k 1}, q_{k 2}, \ldots, q_{k j}\right): \text { the set of each indifference } \\
& \text { threshold for each criterion } j \text { in class } k \text {. }
\end{aligned}
$$

Given that not all criteria are necessarily considered across all classes, and even when they are, they may vary in their preference functions, weights, or thresholds, depending on their relevance to and influence on each class, and the sets $F_{k}, W_{k}, Q_{k}$, and $P_{k}$ may differ for each class.

Based on these two indices (intensity of membership and intensity of nonmembership), the assignment of an alternative $a_{i}$ to a class $C_{k}$ is determined by the intensity of the assignment $\Pi\left(a_{i}, C_{k}\right)$ described in the following.

Definition 3 (intensity of the assignment). For any alternative $a_{i}$ from $A$ and any MPP $B_{k}$, representing class $C_{k}, \Pi\left(a_{i}, C_{k}\right)=$ $\Pi\left(a_{i}, B_{k}\right)-\Pi\left(B_{k}, a_{i}\right)$ represents the intensity of the assignment of $a_{i}$ to $C_{k}$. Thus, in the proposed method, the objective is to $\max \Pi\left(a_{i}, C_{k}\right)$.

The framework presented in Figure 3 summarizes the proposal through steps divided into three phases (Problem Definition, Evaluation, and Assignment).
The Problem Definition phase comprises the definition as follows:

(i) The set of $n$ alternatives: $A=\left(a_{1}, a_{2}, \ldots, a_{i}\right)$, where $i=$ $1, \ldots, n$, that must be assigned to some nonordered classes;

(ii) The set of $c$ nonordered classes: $C=\left(C_{1}, C_{2}, \ldots, C_{k}\right)$, where $k=1, \ldots, c$;

(iii) The set of $m$ criteria: $G=\left(g_{1}, g_{2}, \ldots, g_{j}\right)$, where $j=1, \ldots, m$, which comprises all the criteria used to define the classes and specifies which alternatives will be evaluated.

For each class $k$, the following sets are also defined:

(i) MPPs: $B_{k}=\left(b_{k 1}, b_{k 2}, \ldots, b_{k j}\right)$;

(ii) Criteria weights: $W_{k}=\left(w_{k 1}, w_{k 2}, \ldots, w_{k j}\right)$;

(iii) Preference thresholds: $P_{k}=\left(p_{k 1}, p_{k 2}, \ldots, p_{k j}\right)$;

(iv) The indifference thresholds: $Q_{k}=\left(q_{k 1}, q_{k 2}, \ldots, q_{k j}\right)$.

In the Evaluation phase, each single alternative $a_{i}$ is compared with each MPP $B_{k}$, and $\Pi\left(a_{i}, B_{k}\right)$ is calculated using (2). Further, each MPP $B_{k}$ is compared with each single alternative $a_{i}$, and $\Pi\left(B_{k}, a_{i}\right)$ is calculated, using (3). Then, $\Pi$ $\left(a_{i}, C_{k}\right)$ is defined for all alternatives as it bears on all classes.

The Assignment phase is performed via the allocation of each alternative $a_{i}$ to a specific class $C_{k}$ as a way of maximizing $\Pi\left(a_{i}, C_{k}\right)$.

In the proposed method, it is possible to apply different criteria subsets to different classes, given the possibility that some criteria may be applicable to characterizing some classes but unnecessary for other classes. It is worth stating that this is a specific characteristic of nominal classification problems and thus does not apply to sorting problems in which classes are ordered and are characterized by the same criteria. Therefore, a unique set of criteria, including all criteria considered for at least one class, is generated. Thus, the set of criteria weights of a class $k$, for example, is represented by the set $W_{k}=\left(w_{k 1}, w_{k 2}, \ldots, w_{k j}\right)$. The value of a given criterion weight represents its relevance to each class. So, when a criterion $g_{2}$, for example, is neither relevant to nor 


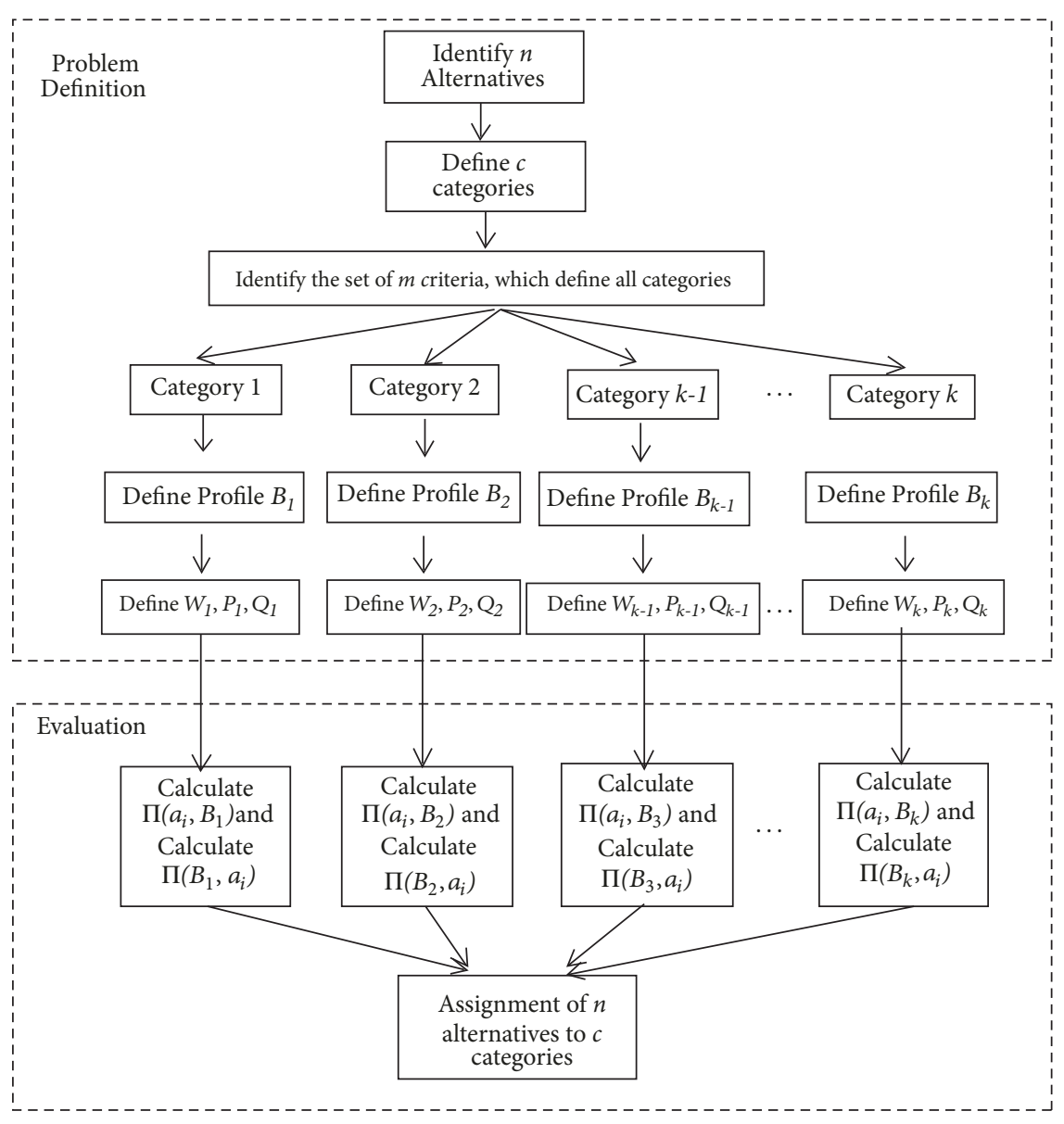

FIGURE 3: Outranking method for nominal classification.

even considered by a specific class $k, w_{k 2}$ assumes a null value. Indeed, other researchers have pointed out the property of criteria flexibility for classes. For instance, [41] claims that criteria weights should be defined in terms of the following two conditions: criterion $g_{j}$ is not pertinent to the assignment of alternative $a_{i}$ to class $C_{k}$ and criterion $g_{j}$ is the only criterion pertinent to the assignment of alternative $a_{i}$ to class $C_{k}$.

In fact, there are several classification problems where some criteria characterize more than one class and some criteria are specific to one class. In medical diagnosis, for example, patients are assessed on the basis of different symptoms (e.g., fever, pain, headache, and cough) characterizing a very heterogeneous group of diseases (classes). According to the medical evaluation of the patient (alternative), given these various symptoms (criteria), the appropriate treatment is prescribed, to maximize the chances of success $[19,41]$.

In addition to the criteria flexibility for classes, given that it may not be appropriate to apply the same criteria set to different classes, another important feature in nominal classification problems, exemplified by the proposed method, is the alternative flexibility for classes, which means that some alternatives may be assigned to more than one class, and others may not be assigned to any class. As in the case of medical diagnoses, the patient could have symptoms that characterize different diseases and require different treatments. However, for the disease that represents the worst condition afflicting patient, the correspondent treatment takes priority. In this way, the minimum profile approach is used to identify the class $\left(C_{k}\right)$ to which an alternative $a_{i}$ gives the maximum contribution (the worse condition in the medical example), using the expression $\max \Pi\left(a_{i}, C_{k}\right)$, by means of assessing the alternative $a_{i}$ for the criteria that characterize the class $C_{k}$.

Therefore, it is important to present formal and explicit definitions of criteria and alternative flexibility for classes.

Definition 4 (criteria flexibility for classes). For each class $C_{k}$, the criterion weight $\left(w_{k j}\right)$ can assume the following values:

(a) 0 , when the criterion $g_{j}$ is not pertinent for the assignment of an alternative $a_{i}$ to class $C_{k}$.

(b) $0<g_{j}<1$, when the criterion $g_{j}$ is not the only pertinent criterion for the assignment of an alternative $a_{i}$ to class $C_{k}$.

(c) 1 , when the criterion $g_{j}$ is the only pertinent criterion for the assignment of an alternative $a_{i}$ to class $C_{k}$.

Definition 5 (alternative flexibility for classes). An alternative $a_{i} \in A$, will be as follows: 
(a) assigned to only one class $C_{k}$, if $\Pi\left(a_{i}, C_{k}\right) \geq 0$ and this is the maximum value when comparing with other $\Pi\left(a_{i}, C_{l}\right)$, where $l \neq k, l=1, \ldots, c$.

(b) assigned to $C_{k} \in S \subset C$, if $\Pi\left(a_{i}, C_{k}\right) \geq 0$ and it is the maximum value when comparing with other $\Pi\left(a_{i}, C_{l}\right)$ where $l \neq k, l=1, \ldots, c$ and if $\Pi\left(a_{i}, C_{t}\right)=\Pi\left(a_{i}, C_{k}\right)$, $\forall C_{t} \in S, t=1, \ldots, s$.

(c) not assigned to any class $C_{k}$, if $\Pi\left(a_{i}, C_{k}\right)<0 \forall k$, $k=1$...c.

Despite the importance of flexibility, in relation to both criteria and alternatives, there are only a few works described in the literature, such as [33], which approach this flexibility in the context of proposing models for nominal classification. This flexibility is a particularly strong characteristic of the method proposed in the present work.

Other important properties, regarding nominal classification methods, are proposed by Costa et al. (2018) and regard the operations of merging, splitting, adding, and removing.

Definition 6 (merging operation). If two different classes, $C_{l}$ and $C_{s}$, characterized by MPPs $B_{l}$ and $B_{s}$, respectively, are merged to become a new one, $C_{t}$, characterized by the MPP $B_{t}$, then $B_{t}=\left\{B_{t 1}=\min \left\{B_{l 1}, B_{s 1}\right\}, B_{t 2}=\right.$ $\left.\min \left\{B_{l 2}, B_{s 2}\right\}, \ldots, B_{t j}=\min \left\{B_{l j}, B_{s j}\right\}\right\}$. As a result, all the alternatives previously assigned to classes $C_{l}$ and $C_{s}$ will be assigned to this new class $C_{t}$.

Definition 7 (splitting operation). If one class $C_{t}$, characterized by the MPP $B_{t}$, is separated into two different classes, $C_{l}$ and $C_{s}$, characterized by two new MPPs $B_{l}$ and $B_{s}$, respectively, then one of new classes is characterized by the MPP $B_{t j}$, that is, $B_{l j}$ or $B_{s j}=B_{t j}$, for all criteria $j$. Consequently, all the alternatives previously assigned class $C_{t}$ will be assigned to the new classes $C_{l}$ and $C_{s}$.

Definition 8 (adding classes operation). If one class $C_{t}$ is included in the problem, this operation leads to build a new MPP as well as the set of criteria weights for this class. Such a new class may receive alternatives previously assigned to other classes and alternatives which were previously not assigned to any class.

Definition 9 (removing classes operation). If one class $C_{t}$ is removed from the problem, alternatives previously assigned to this class may be assigned to one, more than one, or none of the remaining classes.

The next section furnishes a better understanding of the proposed method through the application of the method to a real-world problem.

\section{Application}

To illustrate the proposal, this paper presents a real-world application that uses real data presented by [34], concerning the problem of assigning retailers to use bank services. The real-world problem involved a Greek bank aiming to reorganize its electronic payment network of retailers equipped with terminals for online payments. To improve service efficiency, the bank wants to assign retailers to four predefined nonordered classes that represent the potential and profitability characteristics, according to specific criteria. The bank uses a two-dimensional evaluation framework, which comprises the retailer's site potential and profitability dimensions to classify retailers.

Following the framework proposed in Figure 2, for this example, in the Problem Definition phase, the following were defined:

(i) 20 alternatives: 20 retailers, $\mathrm{A}=\left(a_{1}, a_{2}, \ldots, a_{20}\right)$ and

(ii) 4 nonordered classes, $C=C_{1}, C_{2}, \ldots, C_{4}$, described in Table 2.

The four classification classes (Table 2), defined on the basis of this segmentation, depict the importance of the retailer to the bank.

Further, the classes are also linked to a marketing strategy that the bank will follow as a result of the classification.

(i) 13 criteria, $\mathrm{G}=\left(g_{1}, g_{2}, \ldots, g_{13}\right)$, grouped into financial and nonfinancial dimensions, as shown in Table 3;

(ii) 4 profiles, $B_{k}=\left(b_{k 1}, b_{k 2}, \ldots, b_{k 13}\right)$; and

(iii) the set of criterion weights $W_{k}=\left(w_{k 1}, w_{k 2}, \ldots, w_{k 13}\right)$, which, in this problem, is the same for all classes.

Data regarding the evaluations of alternatives, criterion weights, and MPP of the classes are shown in Table 4.

Figure 4 illustrates the idea of MPPs, considering the minimum performance profiles $\left(b_{1}\right.$ and $\left.b_{2}\right)$ required for 2 classes $\left(C_{1}\right.$ and $\left.C_{2}\right)$ for 5 of the 13 criteria.

As can be seen in Figure 3, the MPPs for this application do not set boundaries between classes, as expected in nominal classification methods. It worth noting, further, that the profile of class 2 (blue line) is below the profile of class 1 (red line) for criteria $g_{1}, g_{2}$, and $g_{3}$, but the profile of class 2 is above the profile of class 1 for criteria $g_{4}$ and $g_{5}$.

(i) 4 sets of preference thresholds, $p_{k}=\left(p_{k 1}, p_{k 2}, \ldots\right.$, $\left.p_{k 13}\right)$ and

(ii) 4 sets of indifference thresholds, $q_{k}=\left(q_{k 1}, q_{k 2}, \ldots\right.$, $\left.q_{k 13}\right)$.

The data regarding preference and indifference thresholds for each class $C_{k}$ according to each criterion $g_{j}$ are shown in Table 5 and in Table 6 . The values determined for this problem are exactly the same for all criteria and classes.

The results of the Evaluation phase, where $\Pi\left(a_{i}, b_{k}\right), \Pi$ $\left(b_{k}, a_{i}\right)$, and $\Pi\left(a_{i}, C_{k}\right)$ are calculated, can be seen in Appendix. Finally, the Assignment phase is performed through the allocation of each alternative $a_{i}$ to a specific class $C_{k}$ as a way to maximize $\Pi\left(a_{i}, C_{k}\right)$. Table 7 summarizes results of the comparison of this nominal classification proposal with three methods: the NeXClass by [37], the method presented by [35], and the one proposed by [33] - adapted for this example. The methods used in these three papers, as proposed in this paper, aim to help the DM address a nonordinal classification problem. Details about them were presented in the initial sections. 
TABLE 2: Classes for retailer classification [34].

\begin{tabular}{|c|c|c|c|c|}
\hline Class specification & $C_{1}$ & $C_{2}$ & $C_{3}$ & $\mathrm{C}_{4}$ \\
\hline Definition & $\begin{array}{l}\text { Retailers with relative } \\
\text { low potential and } \\
\text { medium to high } \\
\text { profitability. }\end{array}$ & $\begin{array}{l}\text { Retailers with relative } \\
\text { high potential and } \\
\text { medium to high } \\
\text { profitability. }\end{array}$ & $\begin{array}{c}\text { Retailers with } \\
\text { minimum to high } \\
\text { potential and medium } \\
\text { to low profitability. }\end{array}$ & $\begin{array}{c}\text { Retailers with } \\
\text { medium to low } \\
\text { potential and low } \\
\text { profitability. }\end{array}$ \\
\hline Strategy & $\begin{array}{c}\text { Bank will allocate } \\
\text { substantial resources } \\
\text { to strengthen retailer's } \\
\text { potential. }\end{array}$ & $\begin{array}{l}\text { Bank will allocate } \\
\text { maximum resources } \\
\text { to provide high added } \\
\text { value innovative } \\
\text { services. }\end{array}$ & $\begin{array}{l}\text { Bank will minimize } \\
\text { resource allocation } \\
\text { and focus to top } \\
\text { retailers of the class. }\end{array}$ & $\begin{array}{l}\text { Bank will screen } \\
\text { retailers for potential } \\
\text { development, } \\
\text { allocating a minimum } \\
\text { level of resources. }\end{array}$ \\
\hline
\end{tabular}

TABLE 3: Criteria for the evaluation of retailers [37].

\begin{tabular}{|c|c|c|}
\hline Criterion & Definition & Scale \\
\hline$g_{1}$ & Retailer size (average daily sales in 1000 Euros) & $1-100$ \\
\hline$g_{2}$ & Intensity of EFT/PoS (percentage of daily sales through EFT/PoS & $1-100$ \\
\hline$g_{3}$ & Average value per EFT/PoS transaction (in Euros) & $1-100$ \\
\hline$g_{4}$ & Average cost per EFT/PoS terminal (in Euros) & $1-100$ \\
\hline$g_{5}$ & $\begin{array}{l}\text { EFT/PoS terminal profitability (average monthly revenue per terminal [in Euros]/average monthly cost per } \\
\text { terminal [in Euros]) }\end{array}$ & $1-100$ \\
\hline$g_{6}$ & Average growth rate (indicator showing monthly increase in transaction ratio) & $1-100$ \\
\hline$g_{7}$ & Merchant class (based on bank's merchant type definition, according to merchant activity) & $1-100$ \\
\hline$g_{8}$ & Collaboration efficiency (index based on merchants calls to bank support center) & $1-100$ \\
\hline$g_{9}$ & $\begin{array}{l}\text { Exclusivity (index based on retailer's exclusive collaboration; normally a retailer has installed at the same place } \\
\text { EFT/PoS terminals from several competing banks) }\end{array}$ & $1-100$ \\
\hline$g_{10}$ & Location (Index based on retailer's distance factors from areas with high traffic) & $1-100$ \\
\hline$g_{11}$ & Opening hours (index based on retailer's opening hours) & $1-100$ \\
\hline$g_{12}$ & Training of employees (index expressing employees' expertise on EFT/PoS) & $1-100$ \\
\hline$g_{13}$ & Alternative channels (index expressing usage degree of bank's alternative payment channels from retailer) & $1-100$ \\
\hline
\end{tabular}

*EFT/PoS: Electronic Fund Transfer at Point Sale.

Source: [37].

As can be seen, NeXClass [37] differs in three classifications, [35] in one classification, [33] in one classification, and this proposal in one classification, relative to the current procedure. It is important to note that $[33,35]$ did not apply thresholds to the problem; however, the structure with a double threshold (preference and indifference thresholds) used in this paper prevents improper classification, as stated before. Although our results are the same as those seen [35] and differ only in one classification from the results of [33], it is extremely important to analyze the results with different data.

\section{A Scenario Analysis}

Therefore, this paper addresses the robustness of the results obtained by the nominal classification method proposed herein, using this first illustrative example. According to [51], robustness is a key issue in the field of decision-aiding, as well as in operations research. As a result, numerous researchers have recently addressed this issue [51-62] and have proposed the use of performance measures for classification and clustering methods $[63,64]$. The term robustness refers to a capacity for withstanding "vague approximations" and/or "zones of ignorance" to maintain certain properties [51].

In general, the values assigned to the parameters in multicriteria methods are not perfectly defined. Indeed, according to [57], a critical challenge faced by analysts utilizing a multicriteria decision aid (MCDA) framework is the elicitation of the criteria weights. In the proposed method, the aim is to provide recommendations concerning the classification of retailers that remain acceptable for a wide range of values of the parameters. Thus, robustness with respect to different scenarios was assessed by changing some preference parameters, such as criteria weights, profiles of classes, and preference and indifference thresholds. As a result, a total of 138 scenarios were tested: the combination of changing the values of 13 criteria weights, four profiles of classes according to each criterion, and preference and indifference thresholds in $\pm 10 \%$, following similar procedures to those presented in $[19,56]$.

The results of the analysis of 134 scenarios are shown in Table 8 . As can be seen, results are unchanged for 19 out of 20 alternatives. The only alternative showing different classifications, according to different values, for the parameters is 
TABLE 4: Evaluations of alternatives, criterion weights, and MPP of the classes [37].

\begin{tabular}{|c|c|c|c|c|c|c|c|c|c|c|c|c|c|}
\hline & $g_{1}$ & $g_{2}$ & $g_{3}$ & $g_{4}$ & $g_{5}$ & $g_{6}$ & $g_{7}$ & $g_{8}$ & $g_{9}$ & $g_{10}$ & $g_{11}$ & $g_{12}$ & $g_{13}$ \\
\hline$a_{1}$ & 29 & 22 & 28 & 25 & 69 & 25 & 61 & 52 & 25 & 39 & 58 & 61 & 68 \\
\hline$a_{2}$ & 80 & 78 & 88 & 69 & 59 & 30 & 50 & 45 & 48 & 42 & 22 & 15 & 27 \\
\hline$a_{3}$ & 77 & 90 & 88 & 61 & 63 & 28 & 35 & 33 & 51 & 33 & 22 & 28 & 33 \\
\hline$a_{4}$ & 16 & 39 & 26 & 25 & 55 & 25 & 50 & 51 & 43 & 65 & 37 & 38 & 73 \\
\hline$a_{5}$ & 28 & 56 & 51 & 21 & 34 & 8 & 37 & 61 & 30 & 37 & 55 & 66 & 98 \\
\hline$a_{6}$ & 79 & 75 & 80 & 65 & 60 & 25 & 30 & 34 & 22 & 19 & 22 & 18 & 21 \\
\hline$a_{7}$ & 50 & 625 & 54 & 25 & 38 & 21 & 47 & 41 & 40 & 57 & 65 & 65 & 88 \\
\hline$a_{8}$ & 44 & 19 & 31 & 55 & 49 & 29 & 80 & 70 & 73 & 55 & 48 & 29 & 45 \\
\hline$a_{9}$ & 49 & 43 & 28 & 29 & 61 & 22 & 67 & 42 & 25 & 39 & 51 & 62 & 55 \\
\hline$a_{10}$ & 30 & 25 & 30 & 51 & 55 & 44 & 82 & 84 & 90 & 74 & 32 & 15 & 32 \\
\hline$a_{11}$ & 30 & 29 & 32 & 87 & 86 & 80 & 77 & 46 & 28 & 49 & 25 & 29 & 33 \\
\hline$a_{12}$ & 49 & 17 & 54 & 25 & 37 & 21 & 47 & 39 & 42 & 54 & 65 & 55 & 98 \\
\hline$a_{13}$ & 42 & 14 & 27 & 51 & 43 & 22 & 74 & 67 & 69 & 53 & 40 & 25 & 92 \\
\hline$a_{14}$ & 25 & 19 & 26 & 90 & 81 & 79 & 70 & 44 & 32 & 45 & 28 & 24 & 30 \\
\hline$a_{15}$ & 42 & 14 & 27 & 51 & 56 & 46 & 81 & 78 & 82 & 52 & 40 & 25 & 33 \\
\hline$a_{16}$ & 80 & 77 & 79 & 69 & 65 & 22 & 31 & 37 & 28 & 22 & 19 & 21 & 29 \\
\hline$a_{17}$ & 21 & 15 & 22 & 86 & 79 & 83 & 68 & 40 & 30 & 41 & 20 & 19 & 25 \\
\hline$a_{18}$ & 18 & 12 & 25 & 82 & 81 & 79 & 64 & 38 & 29 & 39 & 19 & 15 & 27 \\
\hline$a_{19}$ & 22 & 18 & 26 & 49 & 51 & 41 & 80 & 80 & 86 & 69 & 24 & 11 & 26 \\
\hline$a_{20}$ & 41 & 35 & 44 & 29 & 34 & 21 & 47 & 61 & 50 & 57 & 62 & 61 & 98 \\
\hline$W_{k}$ & 10 & 12 & 4 & 13 & 13 & 8 & 10 & 4 & 4 & 8 & 4 & 8 & 2 \\
\hline$b_{1}$ & 75 & 70 & 75 & 60 & 55 & 20 & 25 & 35 & 20 & 15 & 15 & 10 & 20 \\
\hline$b_{2}$ & 15 & 10 & 20 & 75 & 70 & 75 & 60 & 30 & 25 & 35 & 15 & 10 & 20 \\
\hline$b_{3}$ & 15 & 10 & 20 & 45 & 45 & 40 & 75 & 70 & 75 & 60 & 15 & 10 & 20 \\
\hline$b_{4}$ & 55 & 10 & 20 & 15 & 10 & 20 & 35 & 30 & 40 & 70 & 75 & 60 & 55 \\
\hline
\end{tabular}

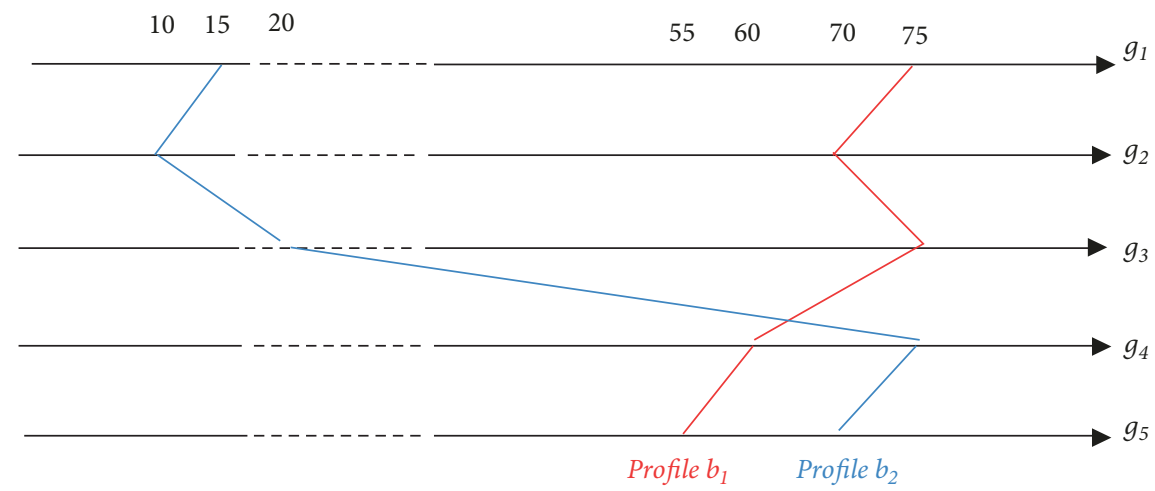

FIgURE 4: Minimum performance profiles (application of Rigopoulos et al., 2010a).

TABLE 5: Preference thresholds for each class, according to each criterion [34].

\begin{tabular}{lccccccccccccc}
\hline$p_{k j}$ & $g_{1}$ & $g_{2}$ & $g_{3}$ & $g_{4}$ & $g_{5}$ & $g_{6}$ & $g_{7}$ & $g_{8}$ & $g_{9}$ & $g_{10}$ & $g_{11}$ & $g_{12}$ & $g_{13}$ \\
\hline$C_{1}$ & 5 & 5 & 5 & 5 & 5 & 5 & 5 & 5 & 5 & 5 & 5 & 5 \\
$C_{2}$ & 5 & 5 & 5 & 5 & 5 & 5 & 5 & 5 & 5 & 5 & 5 & 5 \\
$C_{3}$ & 5 & 5 & 5 & 5 & 5 & 5 & 5 & 5 & 5 & 5 & 5 & 5 \\
$C_{4}$ & 5 & 5 & 5 & 5 & 5 & 5 & 5 & 5 & 5 & 5 & 5 & 5 & 20 \\
\hline
\end{tabular}


TABLE 6: Indifference thresholds for each class, according to each criterion [34].

\begin{tabular}{cccccccccccccc}
\hline$q_{k j}$ & $g_{1}$ & $g_{2}$ & $g_{3}$ & $g_{4}$ & $g_{5}$ & $g_{6}$ & $g_{7}$ & $g_{8}$ & $g_{9}$ & $g_{10}$ & $g_{11}$ & $g_{12}$ & $g_{13}$ \\
\hline$C_{1}$ & 2 & 2 & 2 & 2 & 2 & 2 & 2 & 2 & 2 & 2 & 2 & 2 \\
$C_{2}$ & 2 & 2 & 2 & 2 & 2 & 2 & 2 & 2 & 2 & 2 & 2 & 2 \\
$C_{3}$ & 2 & 2 & 2 & 2 & 2 & 2 & 2 & 2 & 2 & 2 & 2 & 2 \\
$C_{4}$ & 2 & 2 & 2 & 2 & 2 & 2 & 2 & 2 & 2 & 2 & 2 & 2 & 10 \\
\hline
\end{tabular}

TABLE 7: Final classification comparison for the five procedures.

\begin{tabular}{lccccc}
\hline & $\begin{array}{c}\text { NeXClass } \\
{[37]}\end{array}$ & $\begin{array}{c}\text { Method presented } \\
\text { by [35] }\end{array}$ & $\begin{array}{c}\text { Method presented } \\
\text { by [33] }\end{array}$ & $\begin{array}{c}\text { Nominal Classification with } \\
\text { MPP - the method proposed }\end{array}$ & $\begin{array}{c}\text { Existing Procedure } \\
\text { (Benchmarking) }\end{array}$ \\
\hline$a_{1}$ & $C_{4}$ & $C_{4}$ & $C_{3}$ & $C_{4}$ & $C_{3}$ \\
$a_{2}$ & $C_{1}$ & $C_{1}$ & $C_{1}$ & $C_{1}$ & $C_{1}$ \\
$a_{3}$ & $C_{1}$ & $C_{1}$ & $C_{1}$ & $C_{1}$ & $C_{1}$ \\
$a_{4}$ & $C_{3}$ & $C_{4}$ & $C_{3}$ & $C_{4}$ & $C_{4}$ \\
$a_{5}$ & $C_{4}$ & $C_{4}$ & $C_{4}$ & $C_{4}$ & $C_{4}$ \\
$a_{6}$ & $C_{1}$ & $C_{1}$ & $C_{1}$ & $C_{1}$ & $C_{1}$ \\
$a_{7}$ & $C_{4}$ & $C_{4}$ & $C_{4}$ & $C_{4}$ & $C_{4}$ \\
$a_{8}$ & $C_{3}$ & $C_{3}$ & $C_{3}$ & $C_{3}$ & $C_{3}$ \\
$a_{9}$ & $C_{4}$ & $C_{4}$ & $C_{4}$ & $C_{4}$ & $C_{4}$ \\
$a_{10}$ & $C_{3}$ & $C_{3}$ & $C_{3}$ & $C_{3}$ & $C_{3}$ \\
$a_{11}$ & $C_{2}$ & $C_{2}$ & $C_{2}$ & $C_{2}$ & $C_{2}$ \\
$a_{12}$ & $C_{4}$ & $C_{4}$ & $C_{4}$ & $C_{4}$ & $C_{4}$ \\
$a_{13}$ & $C_{4}$ & $C_{3}$ & $C_{3}$ & $C_{3}$ & $C_{3}$ \\
$a_{14}$ & $C_{2}$ & $C_{2}$ & $C_{2}$ & $C_{2}$ & $C_{2}$ \\
$a_{15}$ & $C_{3}$ & $C_{3}$ & $C_{3}$ & $C_{3}$ & $C_{3}$ \\
$a_{16}$ & $C_{1}$ & $C_{1}$ & $C_{1}$ & $C_{1}$ & $C_{1}$ \\
$a_{17}$ & $C_{2}$ & $C_{2}$ & $C_{2}$ & $C_{2}$ & $C_{2}$ \\
$a_{18}$ & $C_{2}$ & $C_{2}$ & $C_{2}$ & $C_{2}$ & $C_{2}$ \\
$a_{19}$ & $C_{3}$ & $C_{3}$ & $C_{3}$ & $C_{3}$ & $C_{3}$ \\
$a_{20}$ & $C_{4}$ & $C_{4}$ & $C_{4}$ & $C_{4}$ & $C_{4}$ \\
\hline
\end{tabular}

$a_{13}$. Depending on these values, $a_{13}$ can be assigned mainly to classes $C_{2}(86.23 \%)$ and $C_{4}(86.96 \%)$. In addition, in $6.52 \%$ of scenarios, $a_{13}$ is assigned to class $C_{3}$, which is the correct class, according to the existing procedure based on heuristics. It is worth noting that the method proposed in this paper assigns $a_{13}$ to the same class $-C_{3}$ (using the initial values for parameters). Moreover, alternative $a_{13}$ is assigned to more than one class in some scenarios analyzed (alternative flexibility for classes feature). In general, these results show that the proposed method leads to robust classification, according to the changes in the preference parameters.

\section{Discussion}

The illustrative example presented in the previous section demonstrates the applicability of the proposal for nominal classification problems using MPPs and it can be seen that the results achieved by this proposed method are similar to those determined by other nominal classification methods, including the existing procedure performed by the bank, which can be used as the benchmark. This example had twenty alternatives, to be assigned to four classes-each characterized by one profile-regarding thirteen criteria, accounting for thirteen preference thresholds and thirteen indifference thresholds. It is worth noting that, for this example, the criterion flexibility for classes was not verified, as all criteria influenced the assignment to the four classes. Thus, the profiles of each class were evaluated according to the same thirteen criteria.

From the example, it is possible to illustrate the importance of intensity of the nonmembership $\Pi\left(b_{k}, a_{i}\right)$ index for a correct assignment. The alternative $a_{9}$, for example, could be assigned to the class $C_{2}$ if only the intensity of the membership index $\Pi\left(a_{i}, b_{k}\right)$ had been taken into account. However, $a_{9}$ was assigned to $C_{4}$ after considering the intensity of the nonmembership index $\Pi\left(b_{k}, a_{i}\right)$. It demonstrates that, despite the fact that $a_{9}$ has good evaluation on some criteria to ensure it belongs to the $C_{2}$ class, this alternative did not meet other important (weighted) criteria for $C_{2}$, caused, in a balanced way, $a_{9}$ to become more pertinent in class $C_{4}$; thus, it was allocated to this class. Still, it is important to highlight that the proposed method aims to maximize the 
TABLE 8: Results of the analysis of scenarios.

\begin{tabular}{|c|c|c|c|c|c|c|}
\hline Alternatives & $C_{1}$ & $C_{2}$ & $C_{3}$ & $C_{4}$ & $\begin{array}{l}\text { The proposed method } \\
\text { (initial values) }\end{array}$ & $\begin{array}{l}\text { Existing Procedure } \\
\text { (Benchmarking) }\end{array}$ \\
\hline$a_{1}$ & & & & $138(100 \%)$ & $C_{4}$ & $C_{3}$ \\
\hline$a_{2}$ & $138(100 \%)$ & & & & $C_{1}$ & $C_{1}$ \\
\hline$a_{3}$ & $138(100 \%)$ & & & & $C_{1}$ & $C_{1}$ \\
\hline$a_{4}$ & & & & $138(100 \%)$ & $\mathrm{C}_{4}$ & $\mathrm{C}_{4}$ \\
\hline$a_{5}$ & & & & $138(100 \%)$ & $C_{4}$ & $C_{4}$ \\
\hline$a_{6}$ & $138(100 \%)$ & & & & $C_{1}$ & $C_{1}$ \\
\hline$a_{7}$ & & & & $138(100 \%)$ & $C_{4}$ & $\mathrm{C}_{4}$ \\
\hline$a_{8}$ & & & $138(100 \%)$ & & $C_{3}$ & $C_{3}$ \\
\hline$a_{9}$ & & & & $138(100 \%)$ & $C_{4}$ & $C_{4}$ \\
\hline$a_{10}$ & & & $138(100 \%)$ & & $C_{3}$ & $C_{3}$ \\
\hline$a_{11}$ & & $138(100 \%)$ & & & $\mathrm{C}_{2}$ & $\mathrm{C}_{2}$ \\
\hline$a_{12}$ & & & & $138(100 \%)$ & $\mathrm{C}_{4}$ & $C_{4}$ \\
\hline$a_{13}$ & & $119(86.23 \%)$ & $9(6.52 \%)$ & $120(86.96 \%)$ & $\mathrm{C}_{3}$ & $C_{3}$ \\
\hline$a_{14}$ & & $138(100 \%)$ & & & $\mathrm{C}_{2}$ & $\mathrm{C}_{2}$ \\
\hline$a_{15}$ & & & $138(100 \%)$ & & $C_{3}$ & $C_{3}$ \\
\hline$a_{16}$ & $138(100 \%)$ & & & & $C_{1}$ & $C_{1}$ \\
\hline$a_{17}$ & & $138(100 \%)$ & & & $\mathrm{C}_{2}$ & $\mathrm{C}_{2}$ \\
\hline$a_{18}$ & & $138(100 \%)$ & & & $\mathrm{C}_{2}$ & $\mathrm{C}_{2}$ \\
\hline$a_{19}$ & & & $138(100 \%)$ & & $C_{3}$ & $C_{3}$ \\
\hline$a_{20}$ & & & & $138(100 \%)$ & $C_{4}$ & $C_{4}$ \\
\hline
\end{tabular}

overall allocation, i.e., to assign the alternative $a_{i}$ to the class $C_{k}$ that leads to $\max \Pi\left(a_{i}, C_{k}\right)$.

Another important characteristic of the present proposal concerns alternative flexibility for classes, which refers to an alternative-according to the intensity of assignment parameter $\Pi\left(a_{i}, C_{k}\right)$-that can be in zero, one, or more classes. The first possibility could occur when the $\Pi\left(a_{i}, C_{k}\right)$ for each class is below a DM's given minimum, such that the alternative does not belong to any class of the problem. A real-life example might involve some candidates, under consideration for employment by a company, one or more of whom cannot be assigned to any job vacancy, given the lack of required skills. The second possibility is the most common: an alternative is assignable to one, and only one, class. The last possibility refers to a situation where an alternative could be assigned to more than one class, due to a difference between two or more of the biggest $\Pi\left(a_{i}, C_{k}\right)$ that is too small or possibly even zero. This was the case for some scenarios considered in the robustness analysis, and it would be the case, in the context of the aforementioned real-life example previously presented, where one or some of the candidates have the skills required for more than one job.

To deal with the alternative flexibility, this work proposes assignment thresholds to be discussed and determined by the DM. These thresholds would be in accordance with a minimum-intensity assignment parameter and indifference between more than one of the biggest intensities of assignment parameters.

One can observe that the proposed method requires the definition of several parameters (criteria weights, preference and indifference thresholds, and MPP) which is a common requirement of most multicriteria methods. For this reason, in the last decades, there has been an increase in research dedicated to elicitation of parameters because the elicitation process is one of the most complex and critical tasks facing research and applications within the field of decision analysis [59]. Indeed, this is especially critical because such parameters can change the position of any alternative in a class [9]. Reference [16], for example, proposed a methodology for the ELECTRE TRI that encompasses this problem, by substituting assignment examples by direct elicitation of the parameters of the model. The values of the parameters are inferred via a certain form of regression on assignment examples, which can be extended to apply to our method.

Another important point is that more than one DM may participate in the nominal classification process and consequently a potential conflict can emerge regarding the numerical values of parameters. An interesting discussion regarding group decision process is provided by [60-62]. Finally, it is worth noting that it is possible to incorporate those methodologies related to the elicitation of parameters for group decision in our method.

\section{Conclusions}

As it can be seen, the type of classification problems which aims to assign alternatives in different classes according to particular characteristics is getting much attention from researchers and practitioners. The method proposed herein has three unique features, namely: flexibility, criterion and 
TABle 9

\begin{tabular}{|c|c|c|c|}
\hline & $\Pi\left(a_{i}, b_{k}\right)$ & $\Pi\left(b_{k}, a_{i}\right)$ & $\Pi\left(a_{n i}, C_{k}\right)$ \\
\hline$a_{1} \times b_{1}$ & 0.8 & 0.2 & 0.6 \\
\hline$a_{1} \times b_{2}$ & 0.7 & 0 & 0.7 \\
\hline$a_{1} \times b_{3}$ & 0.99 & 0 & 0.99 \\
\hline$a_{1} \times b_{4}$ & 0.87 & 0 & 0.87 \\
\hline$a_{2} \times b_{1}$ & 0.8 & 0.2 & 0.6 \\
\hline$a_{2} \times b_{2}$ & 0.6 & 0.4 & 0.2 \\
\hline$a_{2} \times b_{3}$ & 0.31 & 0.68 & -0.37 \\
\hline$a_{2} \times b_{4}$ & 0.45 & 0.39 & 0.06 \\
\hline$a_{3} \times b_{1}$ & 0.4 & 0.6 & -0.2 \\
\hline$a_{3} \times b_{2}$ & 0.9 & 0.1 & 0.8 \\
\hline$a_{3} \times b_{3}$ & 0.62 & 0.37 & 0.25 \\
\hline$a_{3} \times b_{4}$ & 0.84 & 0.16 & 0.68 \\
\hline$a_{4} \times b_{1}$ & 0.923 & 0 & 0.923 \\
\hline$a_{4} \times b_{2}$ & 1 & 0.93 & 0.07 \\
\hline$a_{4} \times b_{3}$ & 0.62 & 0 & 0.62 \\
\hline$a_{4} \times b_{4}$ & 0.768 & 0 & 0.768 \\
\hline$a_{5} \times b_{1}$ & 0.8 & 0.2 & 0.6 \\
\hline$a_{5} \times b_{2}$ & 0.6 & 0.4 & 0.2 \\
\hline$a_{5} \times b_{3}$ & 0.68 & 0.31 & 0.37 \\
\hline$a_{5} \times b_{4}$ & 0.68 & 0.32 & 0.36 \\
\hline$a_{6} \times b_{1}$ & 0.4 & 0.6 & -0.2 \\
\hline$a_{6} \times b_{2}$ & 0.9 & 0.1 & 0.8 \\
\hline$a_{6} \times b_{3}$ & 0.68 & 0.31 & 0.37 \\
\hline$a_{6} \times b_{4}$ & 0.74 & 0.26 & 0.48 \\
\hline$a_{7} \times b_{1}$ & 0.8 & 0.2 & 0.6 \\
\hline$a_{7} \times b_{2}$ & 0.7 & 0.3 & 0.4 \\
\hline$a_{7} \times b_{3}$ & 0.99 & 0 & 0.99 \\
\hline$a_{7} \times b_{4}$ & 0.87 & 0.13 & 0.74 \\
\hline$a_{8} \times b_{1}$ & 0.6 & 0.2 & 0.4 \\
\hline$a_{8} \times b_{2}$ & 0.7 & 0 & 0.7 \\
\hline$a_{8} \times b_{3}$ & 0.302 & 0 & 0.302 \\
\hline$a_{8} \times b_{4}$ & 0.87 & 0 & 0.87 \\
\hline$a_{9} \times b_{1}$ & 0.8 & 0.2 & 0.6 \\
\hline$a_{9} \times b_{2}$ & 0.7 & 0 & 0.7 \\
\hline$a_{9} \times b_{3}$ & 0.68 & 0.31 & 0.37 \\
\hline$a_{9} \times b_{4}$ & 0.61 & 0.26 & 0.35 \\
\hline$a_{10} \times b_{1}$ & 0.2 & 0.8 & -0.6 \\
\hline$a_{10} \times b_{2}$ & 0.6 & 0.292 & 0.308 \\
\hline$a_{10} \times b_{3}$ & 0.68 & 0.31 & 0.37 \\
\hline$a_{10} \times b_{4}$ & 0.61 & 0.343 & 0.267 \\
\hline
\end{tabular}

alternative flexibility for classes; robustness, because it uses concepts of a well-known method (PROMETHEE); and usefulness, many real problems are characterized by MPP for the classes; thus, this novel approach demonstrably addresses this problem.

Moreover, because our method deals with nominal classification problems using the concept of MPP, the alternatives are designed to classes according to the concept of maximizing the overall performance of the assignment taking into account particular characteristics (criteria) of the classes. For instance, suppose that one is analyzing the health condition (class) of a patient (alternative) according to several symptoms (criteria). Using the proposed method, the patient would be assigned to a class in which the treatment would be efficient for all possible diseases.

For future work, given the relative ease of the proposed method and its practical utility, this research may be extended, by using interval operations to deal with imprecise data. Further investigations may account for the study of the proposed assignment thresholds. Yet, some problems may require classifying alternatives by similarity, to allow for comparisons to the profiles of the classes related to a proximity index. An important item to remember is that this proposal is easily modified to address all problems with maximum performance profiles. Finally, another subject for future research is the development of a decision support system (DSS) with the proposed multicriteria method to make it available in a convenient way.

\section{Appendix}

\section{Evaluation Phase for the Illustrative Example}

See Table 9.

\section{Data Availability}

Previously reported real data were used to support this study and are available at [10.3923/jas.2008.443.452]. This prior study is cited at relevant places within the text as reference [34].

\section{Conflicts of Interest}

The authors declare that there are no conflicts of interest regarding the publication of this paper.

\section{Acknowledgments}

The authors would like to thank Universidade Federal de Pernambuco (UFPE) in Recife, Brazil, and the Center for Decision Systems and Information Development (CDSID). The authors would also like to thank CNPQ, the Brazilian National Council for Scientific and Technological Development for the financial support.

\section{References}

[1] A. T. De Almeida, C. A. V. Cavalcante, M. H. Alencar et al., Multicriteria and Multiobjective Models for Risk, Reliability and Maintenance Decision Analysis, International Series in Operations Research \& Management Science, Springer, New York, NY, USA, 2015.

[2] B. Roy, Multicriteria Methodology for Decision Aiding, Kluwer, Dordrecht, Netherlands, 1996.

[3] C. Zopounidis and M. Doumpos, "Multicriteria classification and sorting methods: a literature review," European Journal of Operational Research, vol. 138, no. 2, pp. 229-246, 2002. 
[4] S. M. Hatefi, S. A. Torabi, and P. Bagheri, "Multi-criteria ABC inventory classification with mixed quantitative and qualitative criteria," International Journal of Production Research, vol. 52, no. 3, pp. 776-786, 2014.

[5] D. Mohammaditabar, S. Hassan Ghodsypour, and C. Obrien, "Inventory control system design by integrating inventory classification and policy selection," International Journal of Production Economics, vol. 140, no. 2, pp. 655-659, 2012.

[6] L. Yang, H. Li, J. F. Campbell, and D. C. Sweeney, "Integrated multi-period dynamic inventory classification and control," International Journal of Production Economics, vol. 189, pp. 8696, 2017.

[7] C. Araz and I. Ozkarahan, "Supplier evaluation and management system for strategic sourcing based on a new multicriteria sorting procedure," International Journal of Production Economics, vol. 106, no. 2, pp. 585-606, 2007.

[8] A. J. Brito, A. T. de Almeida, and C. M. M. Mota, "A multicriteria model for risk sorting of natural gas pipelines based on ELECTRE TRI integrating utility theory," European Journal of Operational Research, vol. 200, no. 3, pp. 812-821, 2010.

[9] M. M. Silva, A. P. C. S. Costa, and A. P. H. De Gusmão, "Continuous cooperation: A proposal using a fuzzy multicriteria sorting method," International Journal of Production Economics, vol. 151, pp. 67-75, 2014.

[10] R. Bisdorff, "Electre-like clustering from a pairwise fuzzy proximity index," European Journal of Operational Research, vol. 138, no. 2, pp. 320-331, 2002.

[11] J. R. Figueira, Y. De Smet, B. Mareschal, and J.-P. Brans, "MCDA methods for sorting and clustering problems: Promethee tri and promethee cluster," Technical Report IS-MG 2004/02, Universite Libre de Bruxelles/SMG, 2004.

[12] E. Fernandez, J. Navarro, and S. Bernal, "Handling multicriteria preferences in cluster analysis," European Journal of Operational Research, vol. 202, no. 3, pp. 819-827, 2010.

[13] Y. De Smet, P. Nemery, and R. Selvaraj, "An exact algorithm for the multicriteria ordered clustering problem," Omega, vol. 40, no. 6, pp. 861-869, 2012.

[14] G. Kou, Y. Lu, Y. Peng, and Y. Shi, "Evaluation of classification algorithms using MCDM and rank correlation," International Journal of Information Technology \& Decision Making, vol. 11, no. 1, pp. 19-225, 2012.

[15] G. Kou, Y. Peng, and G. Wang, "Evaluation of clustering algorithms for financial risk analysis using MCDM methods," Information Sciences, vol. 275, pp. 1-12, 2014.

[16] V. Mousseau and R. Slowinski, "Inferring an ELECTRE TRI model from assignment examples," Journal of Global Optimization, vol. 12, no. 2, pp. 157-174, 1998.

[17] P. Nemery and C. Lamboray, "FlowSort: a flow-based sorting method with limiting or central profiles," TOP, vol. 16, no. 1, pp. 90-113, 2008.

[18] M. Doumpos and C. Zopounidis, "A multicriteria classification approach based on pairwise comparisons," European Journal of Operational Research, vol. 158, no. 2, pp. 378-389, 2004.

[19] A. S. Costa, J. R. Figueira, and J. Borbinha, "A multiple criteria nominal classification method based on the concepts of similarity and dissimilarity," European Journal of Operational Research, vol. 271, no. 1, pp. 193-209, 2018.

[20] B. Roy and D. Bouyssou, "Aide multicritère à la décision: méthodes et cas," Econômica, 1993.

[21] W. Yu, Aide multicritère à la décision dans le cadre de la problématique du tri: concepts, méthodes et applications, [Ph.D. thesis], Université Paris-Dauphine, 1993.
[22] J. Almeida-Dias, J. R. Figueira, and B. Roy, "Electre Tri-C: A multiple criteria sorting method based on characteristic reference actions," European Journal of Operational Research, vol. 204, no. 3, pp. 565-580, 2010.

[23] J. Almeida-Dias, J. R. Figueira, and B. Roy, "A multiple criteria sorting method where each category is characterized by several reference actions: the Electre Tri-nC method," European Journal of Operational Research, vol. 217, no. 3, pp. 567-579, 2012.

[24] A. Ishizaka and P. Nemery, "Assigning machines to incomparable maintenance strategies with ELECTRE-SORT," Omega, vol. 47, pp. 45-59, 2014.

[25] C. Araz and I. Ozkarahan, "A multicriteria sorting procedure for financial classification problems: the case of business failure risk assessment," in Proceedings of the International Conference on Intelligent Data Engineering and Automated Learning, pp. 563570, Springer, Berlin, Germany, 2005.

[26] A. Ishizaka, C. Pearman, and P. Nemery, "AHPSort: an AHPbased method for sorting problems," International Journal of Production Research, vol. 50, no. 17, pp. 4767-4784, 2012.

[27] E. Fernandez and J. Navarro, "A new approach to multi-criteria sorting based on fuzzy outranking relations: the THESEUS method," European Journal of Operational Research, vol. 213, no. 2, pp. 405-413, 2011.

[28] J. Moscarola, "Aide a la decision en presence de criteres multiples fondee sur une procedure trichotomique: methodologieet application," in These de 3eme Cycle Sciences Des Organisations, Universite de Paris Dauphine, 1977.

[29] R. Massaglia and A. Ostanello, "N-tomic: a support system for multicriteria segmentation problems," Multiple Criteria Decision Support, vol. 356, pp. 167-174, 1991.

[30] T. C. S. Machado, P. R. Pinheiro, and I. Tamanini, "OrclassWeb: a tool based on the classification methodology ORCLASS from verbal decision analysis framework," Mathematical Problems in Engineering, vol. 2014, Article ID 238168, 11 pages, 2014.

[31] F. Lolli, A. Ishizaka, and R. Gamberini, "New AHP-based approaches for multi-criteria inventory classification," International Journal of Production Economics, vol. 156, pp. 62-74, 2014.

[32] P. Perny, "Multicriteria filtering methods based on concordance and non-discordance principles," Annals of Operations Research, vol. 80, pp. 137-165, 1998.

[33] Y. Chen, D. Marc Kilgour, and K. W. Hipel, "Multiple criteria classification with an application in water resources planning," Computers \& Operations Research, vol. 33, no. 11, pp. 3301-3323, 2006.

[34] G. Rigopoulos, J. Psarras, and D. T. Askounis, "A decision support system for supervised assignment in banking decisions," Journal of Applied Sciences, vol. 8, no. 3, pp. 443-452, 2008.

[35] A. P. Tchangani, "Selectability/rejectability measures approach for nominal classification," Journal of Uncertain Systems, vol. 3, no. 4, pp. 257-269, 2009.

[36] C. C. G. Famá and L. H. Alencar, "A classification model for managers by competencies: a case study in the construction sector," Mathematical Problems in Engineering, vol. 2017, Article ID 1303916, 16 pages, 2017.

[37] G. Rigopoulos and N. V. Karadimas, "Military student assignment using NexClass decision support system," in Proceedings of the 3rd International Conference on Mathematics and Computers in Sciences and in Industry, MCSI 2016, pp. 213-218, Chania, Greece, August 2016.

[38] G. Rigopoulos, D. T. Askounis, and K. Metaxiotis, "NeXCLass: a decision support for non-ordered multicriteria classification," 
International Journal of Information Technology \& Decision Making, vol. 9, no. 1, pp. 53-79, 2010.

[39] G. Rigopoulos and K. Anagnostopoulos, "Fuzzy multicriteria assignment for nominal classification.Methodology and application in evaluation of greek bank's electronic payment retailers," International Journal of Information Technology \& Decision Making, vol. 9, no. 3, pp. 437-454, 2010.

[40] B. Mareschal, Visual PROMETHEE software Preference Function Assistant, Université Libre de Bruxelles, Bruxelles, Belgium, 2011-2013.

[41] N. Belacel, H. B. Raval, and A. P. Punnen, "Learning multicriteria fuzzy classification method PROAFTN from data," Computers \& Operations Research, vol. 34, no. 7, pp. 1885-1898, 2007.

[42] J. Léger and J.-M. Martel, "A multi-criteria assignment procedure for a nominal sorting problematic," European Journal of Operational Research, vol. 138, no. 2, pp. 349-364, 2002.

[43] E. Fernandez, J. Navarro, and A. Duarte, "Multicriteria sorting using a valued preference closeness relation," European Journal of Operational Research, vol. 185, no. 2, pp. 673-686, 2008.

[44] A. Scarelli and S. C. Narula, "A multicriteria assignment problem," Journal of Multi-Criteria Decision Analysis, vol. 11, no. 2, pp. 65-74, 2002.

[45] J.-P. Brans and B. Mareschal, "The PROMCALC \& GAIA decision support system for multicriteria decision aid," Decision Support Systems, vol. 12, no. 4-5, pp. 297-310, 1994.

[46] B. Mareschal and J.-P. Brans, "Geometrical representations for MCDA," European Journal of Operational Research, vol. 34, no. 1, pp. 69-77, 1988.

[47] J.-P. Brans and P. Vincke, "A preference ranking organisation method: the PROMETHEE method for MCDM," Management Science, vol. 31, no. 6, pp. 647-656, 1985.

[48] J.-P. Brans, P. Vincke, and B. Mareschal, "How to select and how to rank projects: the PROMETHEE method," European Journal of Operational Research, vol. 24, no. 2, pp. 228-238, 1986.

[49] E. Chelmis, D. Niklis, G. Baourakis, and C. Zopounidis, "Multiciteria evaluation of football clubs: the Greek superleague," Operational Research, pp. 1-30, 2017.

[50] A. T. de Almeida, Processo de Decisão Nas Organizações: Construindo Modelos De Decisão Multicritério, Atlas, São Paulo, Brazil, 2013.

[51] B. Roy, "Robustness in operational research and decision aiding: a multi-faceted issue," European Journal of Operational Research, vol. 200, no. 3, pp. 629-638, 2010.

[52] S. Corrente, J. R. Figueira, S. Greco, and R. Słowiński, "A robust ranking method extending ELECTRE III to hierarchy of interacting criteria, imprecise weights and stochastic analysis," OMEGA - The International Journal of Management Science, vol. 73, pp. 1-17, 2017.

[53] L. C. Dias, "A note on the role of robustness analysis in decisionaiding processes," in Annales du LAMSADE, vol. 7, pp. 53-70, Université Paris-Dauphine, 2007.

[54] L. Dias, V. Mousseau, J. Figueira, and J. Clímaco, "An aggregation/disaggregation approach to obtain robust conclusions with ELECTRE TRI," European Journal of Operational Research, vol. 138, no. 2, pp. 332-348, 2002.

[55] M. Doumpos, C. Zopounidis, and E. Grigoroudis, Eds., Robustness Analysis in Decision Aiding, Optimization, and Analytic, Springer, 2016.

[56] N. Rangel-Valdez, E. Fernandez, L. Cruz-Reyes, C. GomezSantillan, G. Rivera, and R. Florencia, "Robustness analysis of an outranking model parameters' elicitation method in the presence of noisy examples," Mathematical Problems in Engineering, vol. 2018, Article ID 2157937, 10 pages, 2018.

[57] N. Tsotsolas, A. Spyridakos, E. Siskos, and I. Salmon, "Criteria weights assessment through prioritizations (WAP) using linear programming techniques and visualizations," Operational Research, pp. 1-16, 2016.

[58] A. Spyridakos, N. Tsotsolas, Y. Siskos, D. Yannakopoulos, and I. Vryzidis, "A visualization approach for robustness analysis in multicriteria disaggregation-aggregation approaches," Operational Research, pp. 1-21, 2018.

[59] M. Riabacke, M. Danielson, and L. Ekenberg, "State-of-theart prescriptive criteria weight elicitation," Advances in Decision Sciences, vol. 2012, Article ID 276584, 24 pages, 2012.

[60] J. C. Leyva-López and E. Fernández-González, "A new method for group decision support based on ELECTRE III methodology," European Journal of Operational Research, vol. 148, no. 1, pp. $14-27,2003$.

[61] P. A. Álvarez, D. C. Morais, J. C. Leyva, and A. T. de Almeida, "A multi-objective genetic algorithm for inferring inter-criteria parameters for water supply consensus," in Proceedings of the International Conference on Evolutionary Multi-Criterion Optimization, pp. 218-233, 2016.

[62] T. Fasth, A. Larsson, L. Ekenberg, and M. Danielson, "Measuring conflicts using cardinal ranking: an application to decision analytic conflict evaluations," Advances in Operations Research, Article ID 8290434, 14 pages, 2018.

[63] G. Li, G. Kou, and Y. Peng, "A Group decision making model for integrating heterogeneous information," IEEE Transactions on Systems, Man, and Cybernetics: Systems, vol. 48, no. 6, pp. 982-992, 2018.

[64] G. Kou, D. Ergu, C. Lin, and Y. Chen, "Pairwise comparison matrix in multiple criteria decision making," Technological and Economic Development of Economy, vol. 22, no. 5, pp. 738-765, 2016. 


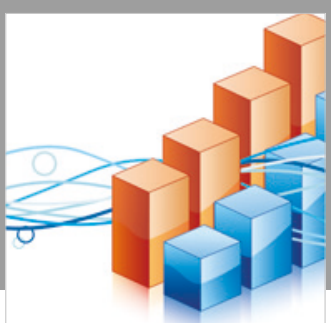

Advances in

Operations Research

\section{-n-m}
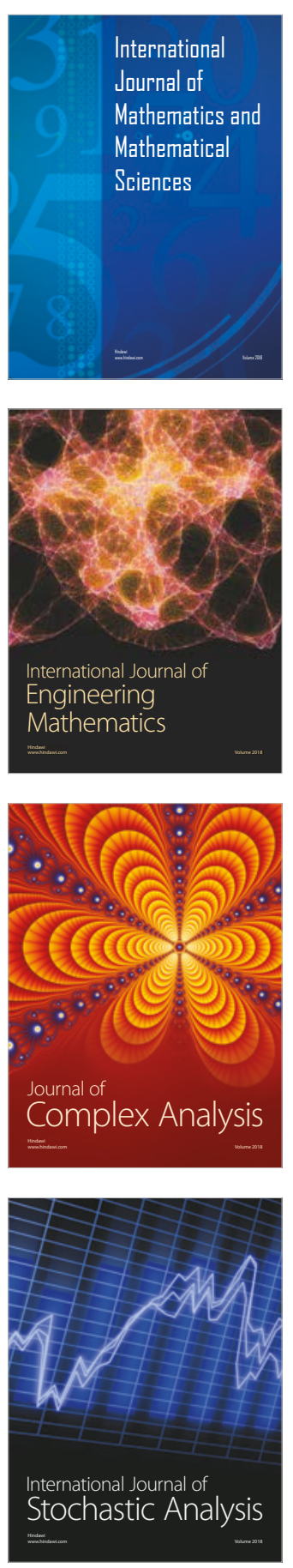
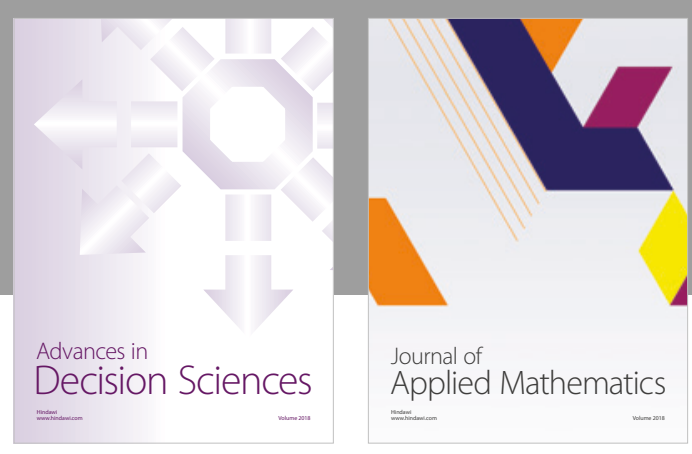

Journal of

Applied Mathematics
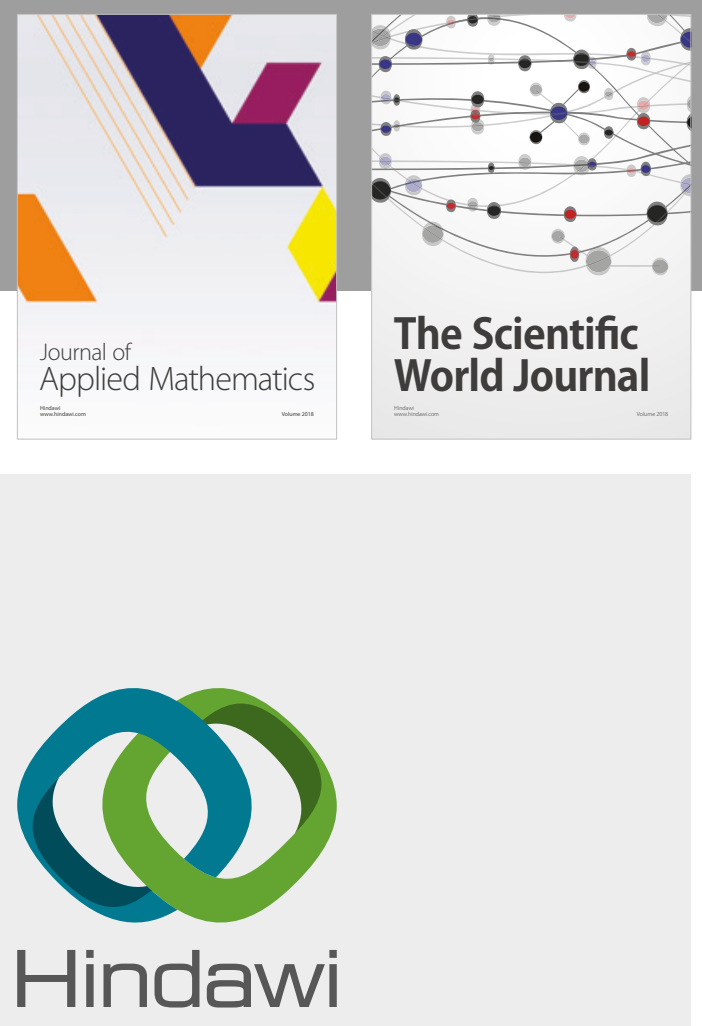

Submit your manuscripts at

www.hindawi.com

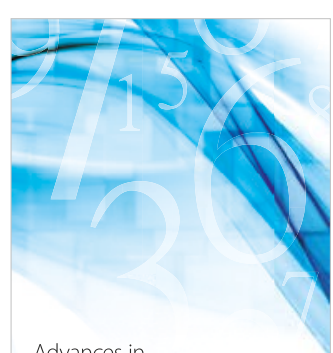

Advances in
Numerical Analysis
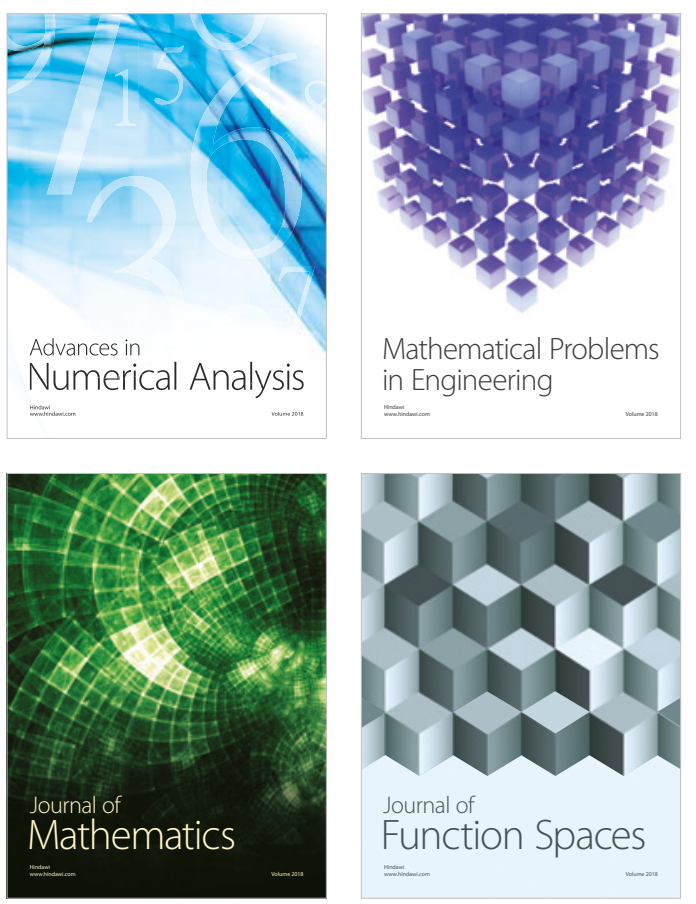

Mathematical Problems in Engineering

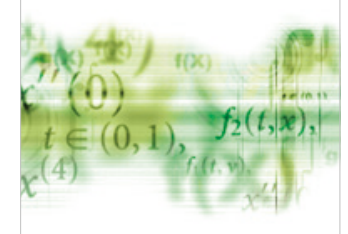

International Journal of

Differential Equations

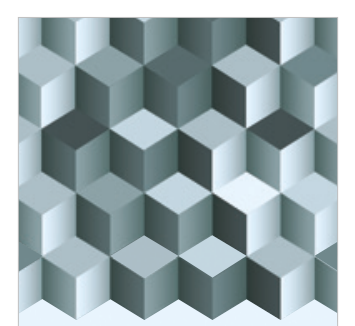

Journal of

Function Spaces

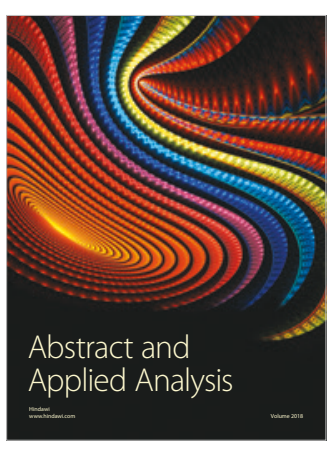

The Scientific

World Journal

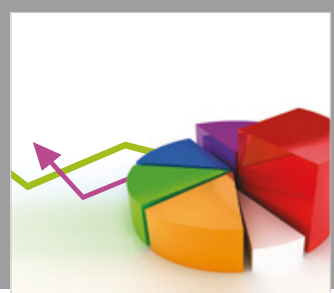

Journal of

Probability and Statistics
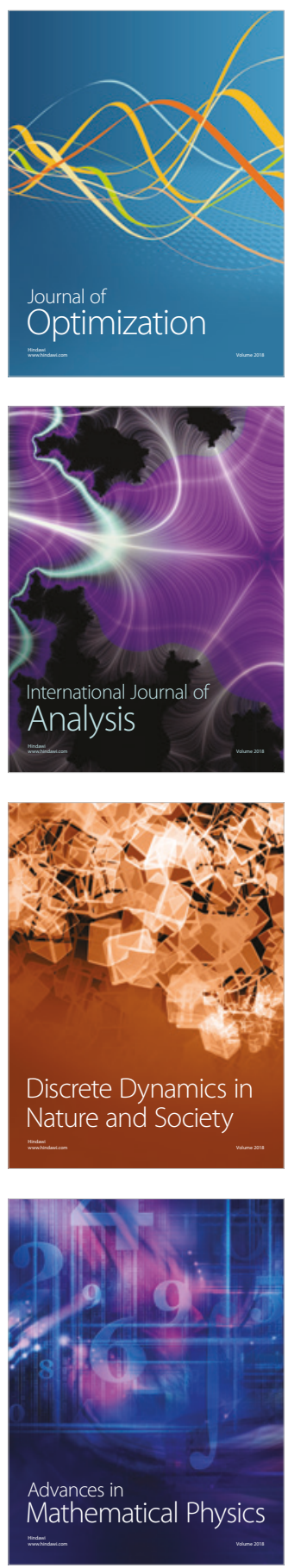